\title{
BMJ Open Missed opportunities to offer HIV tests to high-risk groups during general practitioners' STI-related consultations: an observational study
}

\author{
I K Joore, ${ }^{1}$ D F M Reukers, ${ }^{2}$ G A Donker, ${ }^{3}$ A I van Sighem,,${ }^{4,5}$ E L M Op de Coul, ${ }^{2}$ \\ J M Prins, ${ }^{6}$ S E Geerlings, ${ }^{6}$ R E Barth, ${ }^{5,7}$ J E A M van Bergen, ${ }^{1,2,8}$ \\ I V van den Broek ${ }^{2}$
}

To cite: Joore IK, Reukers DFM, Donker GA, et al. Missed opportunities to offer HIV tests to high-risk groups during general practitioners' STI-related consultations:

an observational study. BMJ Open 2016;6:e009194. doi:10.1136/bmjopen-2015009194

- Prepublication history and additional material is available. To view please visit the journal (http://dx.doi.org/ 10.1136/bmjopen-2015009194).

Received 25 June 2015 Revised 19 November 2015 Accepted 23 November 2015

CrossMark

For numbered affiliations see end of article.

Correspondence to

I K Joore;

i.k.joore@amc.uva.nl

\section{ABSTRACT}

Objectives: Prior research has shown that Dutch general practitioners (GPs) do not always offer HIV testing and the number of undiagnosed HIV patients remains high. We aimed to further investigate the frequency and reasons for (not) testing for HIV and the contribution of GPs to the diagnosis of HIV infections in the Netherlands.

Design: Observational study.

Setting: (1) Dutch primary care network of 42-45 sentinel practices where report forms during sexually transmitted infection (STI)-related consultations were routinely collected, 2008-2013. (2) Dutch

observational cohort with medical data of HIV-positive patients in HIV care, 2008-2013.

Outcome measures: The proportion of STI-related consultations in patients from high-risk groups tested for HIV, with additional information requested from GPs on HIV testing preconsultation or postconsultation for whom HIV testing was indicated, but not performed. Next, information was collected on the profile of HIV-positive patients entering specialised HIV care following diagnosis by GPs.

Results: Initially, an HIV test was reported (360/907) in $40 \%$ of STI-related consultations in high-risk groups. Additionally, in $26 \%$ of consultations an HIV test had been performed in previous or follow-up consultations or at different STI-care facilities. The main reasons for not testing were perceived insignificant risk; 'too' recent risk according to GPs or the reluctance of patients. The initiative of the patient was a strong determinant for HIV testing. GPs diagnosed about one third of all newly found cases of HIV. Compared with STI clinics, HIV-positive patients diagnosed in general practice were more likely to be older, female, heterosexual male or sub-Saharan African.

Conclusions: In one-third of the STI-related consultations of persons from high-risk groups, no HIV test was performed in primary care, which is lower than previously reported. Risk-based testing has intrinsic limitations and implementation of new additional strategies in primary care is warranted.
Strengths and limitations of this study

- The study is carried out in a general practitioner network covering a representative sample of the Dutch population.

- Report forms had limited circumstantial information on potential previous HIV testing.

- We obtained additional information by questionnaire on previous or follow-up consultations and reasons for (not) testing for HIV, which were lacking in prior studies.

\section{INTRODUCTION}

In the Netherlands, an estimated total of 25000 individuals are infected with HIV, 25$34 \%$ of whom are undiagnosed. ${ }^{12}$ In 2013, 1100 HIV patients entered into specialised HIV care, of whom $43 \%$ were late for care (CD4 count $<350$ cells $/ \mathrm{mm}^{3}$ or AIDS-defining event regardless of $\mathrm{CD} 4$ count). ${ }^{1}$ In 2011, Cohen et a $\vec{l}^{3}$ showed that early treatment achieved $96 \%$ reduction in transmission between serodiscordant couples, paving the road for a new additional strategy now known as Treatment as Prevention. Early testing is paramount to an integrated approach aimed at early treatment, reduced transmission, and increased public and individual health benefits.

The general practitioner (GP), who acts as a gatekeeper to care in the Netherlands, is an important point of entrance into care, including the diagnosis of sexually transmitted infections (STIs). ${ }^{4}$ In the Netherlands, more than $99 \%$ of the population is registered at a general practice and $75 \%$ of the Dutch population contacts the GP at least once per year. ${ }^{6}$ Treatment of STIs and care is mainly provided by GPs and STI clinics.

According to the national GP guidelines, patients who belong to high-risk groups 
should be advised to undergo an HIV test together with tests for chlamydia, gonorrhoea, syphilis and hepatitis $\mathrm{B}^{7}$

Previously, we explored STI testing at general practices in the Netherlands, using questionnaire data on STIrelated consultations in the GP sentinel practices between 2008 and 2011. ${ }^{8}$ The study showed that HIV tests were not carried out in $64 \%$ of STI-related consultations involving patients at higher risk for HIV. Especially, men who have sex with men (MSM) and persons from STI-endemic countries were frequently not tested. However, for this study, limited circumstantial information was available from report forms on individual consultations and potential previous HIV testing.

For our current study, we aimed to further investigate the frequency and reasons for (not) testing for HIV as well as the contribution of GPs in the diagnosis of HIV infections in the Netherlands. We therefore collected additional information from GPs to find out more about HIV testing in high-risk groups during STI-related consultations. Next, we compared the profile of HIV-positive patients referred by GPs to specialised HIV care with the characteristics of HIV-positive patients diagnosed in STI clinics.

\section{METHODS}

Data on HIV testing and diagnosis were retrieved from two data sources between 2008 and 2013: (1) a consultation-based data set from the Sentinel Practices of the NIVEL Primary Care Database, which provided information on HIV testing in STI-related consultations in general practices in the Netherlands. For every STI consultation in specific high-risk groups where HIV testing was indicated (according to the guidelines) but not performed, an additional questionnaire was sent to the GP to retrieve more information on HIV testing preconsultation or postconsultation. ${ }^{9}$ (2) The ATHENA national observational HIV cohort from the Dutch 'Stichting HIV Monitoring' (SHM) provided information on HIV-positive persons receiving specialised HIV care. ${ }^{1}$

\section{National STI guidelines for GPs: high-risk groups}

The populations at higher risk for STIs, including HIV (high-risk groups), are defined in Dutch national guidelines as: MSM, commercial sex workers (CSW), clients of CSW, people from countries where STIs are endemic, people with three or more partners in the past 6 months and people with a partner in one of these high-risk groups. ${ }^{7}$ Patients from high-risk groups are recommended to be tested for all five major STIs: chlamydia, gonorrhoea, hepatitis B, syphilis and HIV. ${ }^{7}$ Patients who are diagnosed with an STI should be evaluated in terms of patient's history and symptoms to determine whether they should be further tested for STIs.

STI-endemic countries are described on the website of the National Institute for Public Health and the Environment (RIVM) - a pragmatic list of countries known to have a higher prevalence among the population for STI, including HIV, compared with countries with a lower STI prevalence, which can be used for daily practice, has been posted. $^{7}{ }^{10}$

\section{Data collection}

NIVEL Primary Care Database-Sentinel Practices

The Sentinel Practices of the NIVEL Primary Care Database included 42-45 practices and 59 GPs, and covered a population of about $0.8 \%$ of the total Dutch population, nationally representative by age, sex, geographical distribution and population density. ${ }^{8} 9$ Participating GPs register episodes, comprising of one or more consultations, using International Classification of Primary Care (ICPC) codes, also concerning STI issues. ${ }^{11} 12$ Since 2008, GPs are requested to complete a report form in case of an STI-related consultation (see online supplementary file 1). These reports are collected by the NIVEL and completed encoded forms are sent annually to the RIVM. The NIVEL and RIVM constructed the report forms to collect surveillance data similar to information obtained from STI clinics. The report forms contain information on STI testing and diagnosis, patient demographics, reason for consultation, risk behaviour and questions about HIV (risk); and questions about who initiated discussing HIV during this consultation and reasons for testing or not testing for HIV. Also, an additional laboratory report of test results is collected. The GPs receive instructions for these report forms annually.

As part of our study, more information was requested in June 2014 from GPs for STI-related consultations in the period 2008-2013 in which no HIV test was performed (see online supplementary file 1 ). The additional questionnaires were sent by mail to GPs concerning STIrelated consultations in patients who belong to the two main high-risk groups for HIV in the Netherlands: MSM or persons from STI-endemic countries. ${ }^{1}$ The two most common high-risk groups were included in the study to avoid excessive workload. The questionnaire was discussed with a GP epidemiologist, a coordinator from the Sentinel Practices and a GP working at the Department of General Practice at the Academic Medical Center of the University of Amsterdam. The questionnaire addressed whether patients had been tested recently, during a previous or follow-up consultation (within a time window of 6 months) or at a different STI care facility and, if not, reasons for not testing for HIV. GPs collected the information retrospectively from the patient's electronic medical record.

Formal approval for this research project by a medical ethics committee was not required under Dutch law. Patients in the participating practices are informed about the use of encoded patient data for NIVEL surveillance and research, and can opt out of participation, but rarely make use of this option. The NIVEL office requested the additional information from the GP by using an identifiable key (patient code, date of birth 
and date of consultation) based on which the GP could elicit the required information retrospectively from the electronic medical record. The researchers of the study had no access to trace the patient and participating GP records.

\section{ATHENA national observational HIV cohort}

In order to examine the proportion of all new HIV diagnoses registered in specialised HIV care originating from the general practice and compare the characteristics of this group to those of the patients who were diagnosed in STI clinics, data on HIV-positive patients who entered care between 2008 and 2013 were obtained from the ATHENA cohort, which monitors all registered HIV-infected persons from the $31 \mathrm{HIV}$ treatment centres, including 4 paediatric centres. The encoded data set includes age, gender, region of origin (country of birth), location of referral/diagnosis and route of transmission.

\section{Data analysis}

NIVEL data were pooled over 6 years, from 2008 until 2013, to increase statistical power. Univariate and multivariate logistic regression was performed to identify the main determinants for receiving an HIV test in the general practice. Only variables from the univariate analysis with $\mathrm{p} \geq 0.2$ were included in the multivariate analysis. We used a univariate logistic regression for the ATHENA cohort data to investigate potential associations between patient characteristics; and the probability of being diagnosed in the general practice or STI clinic. We used SPSS V.19.0 software (IBM, USA) for statistical analysis.

\section{RESULTS}

\section{HIV testing in general practice}

From 2008 to 2013, 3209 STI-related consultations were registered in the NIVEL database, representing 3006 individual patients, of whom 185 patients had two consultations and 9 had three consultations. In the total group of consultations, 960 HIV tests $(30 \%)$ were performed in the low-risk and high-risk groups.

\section{HIV testing during STI-related consultations by patient group}

The majority of the HIV tests, $82 \%$, were performed during STI-related consultations in people of Dutch origin, and $54 \%$ in females. HIV testing rates during STI-related consultations were similar in persons from STI-endemic countries and in persons of Dutch origin (table 1). The highest percentage of HIV tests was performed during STI-related consultations in patients reporting paid sex contacts (adjusted OR (aOR) 4.6, 95\% CI 2.1 to 10.1 compared with persons in a steady partnership; table 1) and in patients providing 'coming for a periodical check-up' as the reason for consultation (aOR 6.9, 95\% CI 5.5 to 8.7 compared with persons arriving with STI symptoms); 'partner was unfaithful' (aOR 8.1, 95\% CI 5.2 to 12.8) or 'fear of STI' (aOR 4.9,
95\% CI 3.3 to 7.3 ). Only $27 \%$ of STI-related consultations with people who were notified for any STI by a partner were tested for HIV (aOR 2.1, 95\% CI 1.6 to 2.8, compared with persons arriving with STI symptoms) even if they belonged to a high-risk group; MSM who were notified for any STI were tested for HIV in $36 \%$ of consultations and notified persons from STI-endemic countries in $24 \%$ of consultations. MSM with symptoms were tested for HIV in $33 \%$ of consultations and persons from STI-endemic countries with symptoms in $16 \%$ of the consultations.

In total, 18 STI-related consultations were linked to a positive HIV result, 11 patients were known to be HIV positive while 7 received a positive test result during the current STI-related consultation.

\section{HIV testing: initiative and reason}

The initiative $(n=803)$ and reason $(n=705)$ for HIV testing were not recorded for all 960 STI-related consultations. In 23\% of the HIV-related consultations, the GP initiated the discussion on testing for HIV (184/803). HIV tests were more commonly performed when the initiative to address HIV was taken by the patient $(93 \%)$ rather than by the GP $(64 \%)$. The most common reason for HIV testing reported by the GP was to reassure the patient $(77 \%$; 546/705), while in $17 \%$ of consultations, the reason given was, a potential risk of infection $(120 / 705)$.

\section{HIV-testing in high-risk groups}

As shown in table 1 , the number of and proportions of STI-related consultations in high-risk groups in which an HIV test was performed are: 55 (46\%) for MSM, 134 (29\%) for persons originating from STI-endemic countries, $22(63 \%)$ for patients reporting paid sex contacts, $141(33 \%)$ for partners at risk ("notified by partner for STI or partner unfaithful') and $111(52 \%)$ for persons who had three or more sex partners in the past 6 months.

\section{Additional questionnaires sent to GPs}

As shown in figure 1, 907 (28\%) of the STI-related consultations concerned high-risk groups for HIV. In $60 \%$ (547/907) of these no HIV test was performed. To obtain more information on STI-related consultations without HIV testing in the report form, we selected the consultations from the high-risk groups-MSM or persons from STI-endemic countries. Median time between the date of STI-related consultation and date of sending the additional questionnaire was 2 years (IOR $1-4)$. A total of 371 STI-related consultations were eligible, but 138 were excluded for various reasons (figure 1 ). We received a $70 \%$ questionnaire response rate from GPs $(164 / 233)$, but 18 of these $(11 \%)$ could not be retraced in the patient records, leaving 146 questionnaires for analysis. The GPs reported that in $44 \%$ $(\mathrm{N}=64)$ of STI-related consultations an HIV test had been performed during a previous or follow-up consultation, or at a different STI care facility. Six unique 
Table 1 Number of HIV tests and odds of receiving an HIV test during STI-related consultations by demographics and behavioural risk factors, Sentinel Practices of the NIVEL Primary Care Database, 2008-2013

\begin{tabular}{|c|c|c|c|c|c|c|c|}
\hline & \multicolumn{7}{|c|}{ HIV testing $\mathbf{n}(\%)$ in STI-related consultations, $\mathbf{N}$} \\
\hline & \multicolumn{2}{|c|}{$\begin{array}{l}\text { STI-related } \\
\text { consultations }\end{array}$} & \multicolumn{2}{|c|}{ HIV tests } & \multirow{2}{*}{$\begin{array}{l}\text { Percentage } \\
\text { tested } \\
\text { Per cent }\end{array}$} & \multirow{2}{*}{$\begin{array}{l}\text { Univariate } \\
\text { OR }(95 \% \mathrm{Cl})\end{array}$} & \multirow{2}{*}{$\begin{array}{l}\text { Multivariate } \\
\text { aOR (95\% Cl) }\end{array}$} \\
\hline & $\mathbf{N}$ & $\begin{array}{l}\text { Per } \\
\text { cent }\end{array}$ & $\mathbf{n}$ & $\begin{array}{l}\text { Per } \\
\text { cent }\end{array}$ & & & \\
\hline & 3209 & & 960 & & 29.9 & & \\
\hline \multicolumn{8}{|l|}{ Age (years) } \\
\hline$<20$ & 582 & 18.1 & 134 & 14.0 & 23.0 & Ref & Ref \\
\hline 20-29 & 1746 & 54.4 & 543 & 56.6 & 31.1 & 1.5 (1.2 to 1.9$)$ & $1.4(1.1$ to 1.8$)$ \\
\hline $30-49$ & 732 & 22.8 & 235 & 24.5 & 32.1 & 1.6 (1.2 to 2.0$)$ & $1.5(1.2$ to 2.0$)$ \\
\hline$>50$ & 146 & 4.5 & 47 & 4.9 & 32.2 & $1.6(1.1$ to 2.4$)$ & $1.2(0.8$ to 1.9$)$ \\
\hline Missingt & 3 & 0.1 & 1 & 0.1 & 33.3 & - & \\
\hline \multicolumn{8}{|l|}{ Gender and sexual preference } \\
\hline Female & 1884 & 58.7 & 514 & 53.5 & 27.3 & Ref & Ref \\
\hline Heterosexual male* & 1182 & 36.8 & 386 & 40.2 & 32.7 & $1.3(1.1$ to 1.5$)$ & $1.2(1.0$ to 1.4$)$ \\
\hline MSM & 120 & 3.7 & 55 & 5.7 & 45.8 & 2.3 (1.6 to 3.3$)$ & 2.6 (1.7 to 4.0$)$ \\
\hline Missing† & 23 & 0.7 & 5 & 0.5 & 21.7 & - & \\
\hline \multicolumn{8}{|l|}{ Ethnicity } \\
\hline Dutch & 2640 & 82.3 & 791 & 82.4 & 30.0 & Ref & ns \\
\hline Sub-Saharan African & 20 & 0.6 & 10 & 1.0 & 50.0 & $2.3(1.0$ to 5.6$)$ & \\
\hline Antillean/Surinamese & 149 & 4.6 & 41 & 4.3 & 27.5 & $0.9(0.6$ to 1.3$)$ & \\
\hline Turkish/Moroccan & 170 & 5.3 & 54 & 5.6 & 31.8 & $1.1(0.8$ to 1.5$)$ & \\
\hline Other non-western & 116 & 3.6 & 29 & 3.0 & 25.0 & 0.8 (0.5 to 1.2$)$ & \\
\hline Other western & 38 & 1.2 & 18 & 1.9 & 47.4 & 2.1 (1.1 to 4.0$)$ & \\
\hline Missing & 76 & 2.4 & 17 & 1.8 & 22.4 & - & \\
\hline \multicolumn{8}{|l|}{ Relationships (<6 months) } \\
\hline Steady partner & 1479 & 46.1 & 374 & 39.0 & 25.3 & Ref & Ref \\
\hline $\begin{array}{l}\text { Incidental steady/casual } \\
\text { partners }\end{array}$ & 1112 & 34.7 & 391 & 40.7 & 35.2 & $1.6(1.4$ to 1.9$)$ & $1.3(1.0$ to 1.6$)$ \\
\hline Concurrent sexual partners & 123 & 3.8 & 56 & 5.8 & 45.5 & 2.5 (1.7 to 3.6$)$ & $2.0(1.3$ to 3.2$)$ \\
\hline Paid sex contacts & 35 & 1.1 & 22 & 2.3 & 62.9 & $5.0(2.5$ to 10.0$)$ & $4.6(2.1$ to 10.1$)$ \\
\hline Missing & 460 & 14.3 & 117 & 12.2 & 25.4 & - & \\
\hline \multicolumn{8}{|l|}{ Reason for STI-related consultation } \\
\hline STI symptoms & 1463 & 45.6 & 222 & 23.1 & 15.2 & Ref & Ref \\
\hline Notified by partner for any STI & 344 & 10.7 & 92 & 9.6 & 26.7 & 2.0 (1.5 to 2.7$)$ & 2.1 (1.6 to 2.8$)$ \\
\hline Periodic check-up & 558 & 17.4 & 307 & 32.0 & 55.0 & 6.8 (5.5 to 8.5$)$ & $6.9(5.5$ to 8.7$)$ \\
\hline 'Partner unfaithful' & 89 & 2.8 & 49 & 5.1 & 55.0 & $6.8(4.4$ to 10.6$)$ & $8.1(5.2$ to 12.8$)$ \\
\hline Recent risk & 392 & 12.2 & 175 & 18.2 & 44.6 & 4.5 (3.5 to 5.8$)$ & 4.1 (3.2 to 5.3$)$ \\
\hline Fear of STI & 124 & 3.9 & 57 & 5.9 & 46.0 & 4.8 (3.2 to 7.0$)$ & 4.9 (3.3 to 7.3$)$ \\
\hline Referred from STI clinic & 13 & 0.4 & 2 & 0.2 & 15.4 & $1.0(0.2$ to 4.6$)$ & $1.0(0.2$ to 4.7$)$ \\
\hline Missingt & 226 & 7.0 & 56 & 5.8 & 24.8 & - & \\
\hline \multicolumn{8}{|l|}{ Number of partners (<6 months) } \\
\hline $0-1$ & 1716 & 53.5 & 484 & 50.4 & 28.2 & Ref & Ref \\
\hline 2 & 477 & 14.9 & 161 & 16.8 & 33.7 & $1.3(1.0$ to 1.6$)$ & 0.9 (0.7 to 1.2$)$ \\
\hline 3 or more & 213 & 6.6 & 111 & 11.6 & 52.1 & 2.8 (2.1 to 3.7$)$ & 2.0 (1.4 to 2.8$)$ \\
\hline Missingt & 803 & 25.0 & 204 & 21.3 & 25.4 & 1.8 (1.3 to 2.6$)$ & 0.7 (0.6 to 0.9$)$ \\
\hline $\begin{array}{l}\text { Statistical significance indicated in bo } \\
\text { analysis. } \\
\text { The subcategories per risk group are } \\
\text { *Information on sexual preference wa } \\
\text { †Missing; report forms were not comp } \\
\text { are not reported for this group except } \\
\text { †Nine MSM were not tested because } \\
\text { AOR, adjusted OR from multivariate } \\
\text { infection. }\end{array}$ & $\begin{array}{l}\text { <0.05). } \\
\text { ually ex } \\
\text { t given } \\
\text { for all } v \\
\text { he case } \\
\text { y were a } \\
\text { tic regre }\end{array}$ & $\begin{array}{l}\text { Only varial } \\
\text { lusive. } \\
\text { or } 82 \text { men; } \\
\text { ariables; 'n } \\
\text { where ther } \\
\text { ready kno } \\
\text { ssion; MSN }\end{array}$ & $\begin{array}{l}\text { ese me } \\
\text { ing' wt } \\
\text { las a s } \\
\text { to be }\end{array}$ & $\begin{array}{l}\mathrm{n} \text { are } \mathrm{cl} \\
\text { s incluo } \\
\text { gnifican } \\
\text { IV posit } \\
\text { o have }\end{array}$ & $\begin{array}{l}\text { analysis with } p \geq \\
\text { a category in } u \\
\text { ciation (number }\end{array}$ & $\begin{array}{l}0.2 \text { were included in } \\
\text { al. } \\
\text { ivariate and multivar } \\
\text { of partners). }\end{array}$ & $\begin{array}{l}\text { he multivariate } \\
\text { ate analyses; OR's } \\
\text { lly transmitted }\end{array}$ \\
\hline
\end{tabular}

patients of the 146 STI-related consultations (4\%) had previously tested HIV positive.

Combining the reported HIV tests from the additional questionnaire with those reported in the original report form, the total proportion of all STI-related consultations in high-risk groups with an HIV test during or around the time of STI-related consultation was $66 \%$ : $40 \%$ in the same consultation and a further $26 \%$ before 
Figure 1 HIV testing in STIrelated consultations among the two common high-risk groups at the Dutch general practice, 20082013 (GP, general practitioner; MSM, men who have sex with men; STI, sexually transmitted infection).

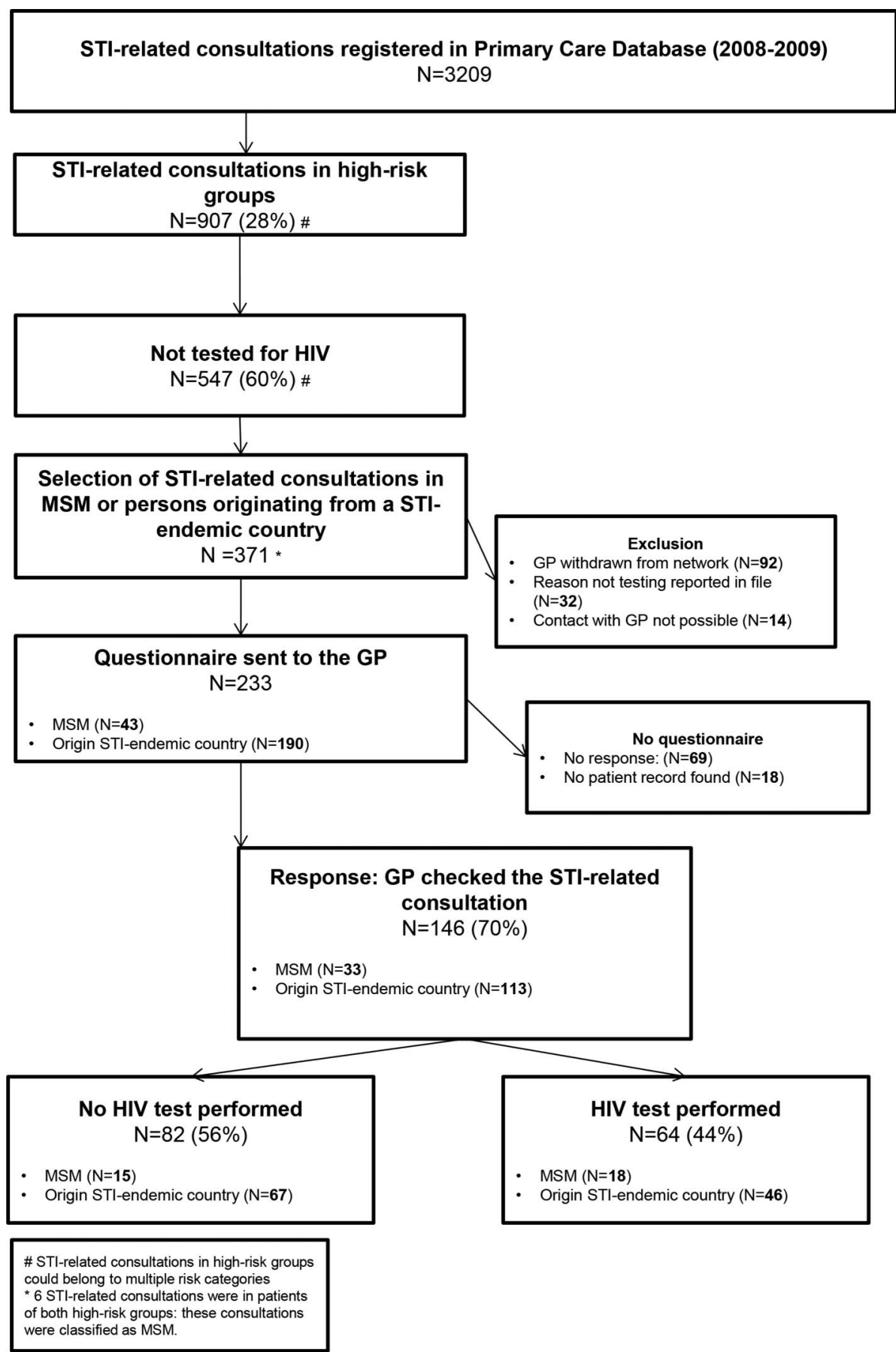

or after that consultation or in another STI care facility ( $44 \%$ of the $60 \%$ initially not tested). For MSM, in $71 \%$ of the STI-related consultations an HIV test was performed in or around the time of the consultation, for persons from STI-endemic countries, $58 \%$.

\section{Reasons for no HIV test in high-risk groups}

In the group of 32 consultations for which a reason for not testing was given in the report forms, the main reasons given were that the patient had not been at risk for HIV transmission $(40 \%)$ or that the time of the risk exposure was too recent $(37 \%)$. GPs also mentioned that the patient hesitated $(14 \%)$ or the patient refused the test $(6 \%)$. In the additional questionnaires, reasons given $(n=55)$ for not testing were, according to the GP, insignificant risk of HIV infection $(53 \%)$, risk of HIV infection was too recent, however, no HIV test was performed during follow-up consultation (11\%), and HIV was discussed but not tested $(18 \%)$, while in $18 \%$ of consultations no HIV test was performed because the patient had not brought up the subject of HIV.

HIV-positive patients in care diagnosed in general practice Of all HIV-positive patients registered in care in the ATHENA cohort between 2008 and 2013, 38\% $(\mathrm{N}=2603)$ were referred from a general practice, $26 \%$ 
$(\mathrm{N}=1818)$ from an STI clinic, 27\% ( $\mathrm{N}=1901)$ from a hospital and 9\% (N=599) from other healthcare settings. Most patients diagnosed by the GP were between 30 and 50 years of age $(\mathrm{N}=1518,58 \%)$. The majority were MSM $(\mathrm{N}=1795,69 \%)$ and/or originated from STI-endemic countries $(\mathrm{N}=739,28 \%)$, of which the largest groups were sub-Saharan Africans $(\mathrm{N}=303,12 \%)$ and Antilleans or Surinamese ( $\mathrm{N}=204,8 \%$; table 2). Compared with HIV-positive patients diagnosed in STI clinics, patients in general practice were more likely to be (1) female (OR 3.3, 95\% CI 2.6 to 4.1) or heterosexual males (OR 3.6, 95\% CI 2.9 to 4.6) than MSM; (2) sub-Saharan African (OR 3.4, 95\% CI 2.6 to 4.4) than Dutch; and (3) 50 years or older (OR 1.6, 95\% CI 1.3 to 1.9 ) than $30-$ 49 years of age.

\section{DISCUSSION}

The national GP guidelines on HIV-testing in high-risk groups were better implemented than was reported in our previous study. ${ }^{7}$ However, data showed that in $34 \%$ of the STI-related consultations from high-risk groups no HIV test was documented.

The main reasons for not testing for HIV were that the GP judged the individual risk for HIV infection as low or that the patient did not want to be tested or to discuss the topic of HIV during the STI-related

Table 2 The ATHENA national observational HIV cohort: age, gender and ethnicity of HIV-positive patients in Dutch specialised HIV care diagnosed in general practice and STI clinic, 2008-2013

\begin{tabular}{|c|c|c|c|c|}
\hline & \multicolumn{2}{|c|}{$\begin{array}{l}\text { General } \\
\text { practice }\end{array}$} & \multicolumn{2}{|c|}{ STI clinic } \\
\hline & $\overline{\mathbf{N}}$ & Per cent & $\overline{\mathbf{N}}$ & Per cent \\
\hline & 2603 & & 1818 & \\
\hline \multicolumn{5}{|l|}{ Age (years) } \\
\hline$<20$ & 57 & 2.2 & 38 & 2.1 \\
\hline 20-29 & 559 & 21.5 & 534 & 29.4 \\
\hline $30-49$ & 1518 & 58.3 & 1040 & 57.2 \\
\hline$>50$ & 469 & 18.0 & 206 & 11.3 \\
\hline Missing & - & - & - & - \\
\hline \multicolumn{5}{|c|}{ Gender and sexual preference } \\
\hline Female & 353 & 13.6 & 97 & 5.3 \\
\hline Heterosexual Male & 361 & 13.9 & 89 & 4.9 \\
\hline MSM & 1795 & 69.0 & 1613 & 88.7 \\
\hline Missing & 94 & 3.6 & 19 & 1.0 \\
\hline \multicolumn{5}{|l|}{ Ethnicity } \\
\hline Dutch & 1636 & 62.9 & 1249 & 68.7 \\
\hline Sub-Saharan & 303 & 11.6 & 69 & 3.8 \\
\hline \multicolumn{5}{|l|}{ African } \\
\hline Antillean/ & 204 & 7.8 & 135 & 7.4 \\
\hline \multicolumn{5}{|l|}{ Surinamese } \\
\hline Turkish/Moroccan & 49 & 1.9 & 26 & 1.4 \\
\hline Other western & 228 & 8.8 & 195 & 10.7 \\
\hline Other non-western & 183 & 7.0 & 144 & 7.9 \\
\hline Missing & - & - & - & - \\
\hline
\end{tabular}

consultation. This indicates that GPs evaluate the situation of individual patients in order to determine whether patients classified in a 'high-risk group' should be tested for HIV. Also, the initiative or the opinion of the patient is of influence for the choice of whether or not to perform an HIV test. Notably, in some STI-related consultations for where the GP reported that the risk of HIV infection was too recent, no HIV test was reported in follow-up consultations.

GPs diagnosed more than one-third of HIV patients who entered care in the Netherlands between 2008 and 2013. Compared with STI clinics, HIV-positive patients diagnosed in general practice were more likely to be older, female, heterosexual male or sub-Saharan African.

This study was carried out in a GP network covering a representative sample of the Dutch population. We obtained additional information on previous or follow-up consultations and reasons for (not) testing for HIV, which was lacking in prior studies. The preceding study, using the same source of initial data on STI-related consultations from the GP sentinel surveillance, found that $64 \%$ of the patients in high-risk groups were not tested according to the national guidelines in place between 2008 and 2011, but contextual information was lacking. Our study observed that the proportion of STI-related consultations in high-risk groups not tested for HIV was lower $(34 \%)$, as HIV tests were performed in previous or follow-up consultations or at a different facility such as an STI clinic, showing the importance of additional background information necessary for meaningful interpretation.

Our analysis focused on the number of STI-related consultations and not on individual patients. As a result, persons may have been counted multiple times depending on how many consultations they had had over the past 6 years, so that the sociodemographic profile of the patient population may be biased towards those testing multiple times. However, the majority of STI-related consultations represented unique patients (3006/3209). Moreover, our opinion is that consultation-based analysis is more accurate, because for each patient consultation the GP performed a new sexual risk assessment, so that one patient could be classified with a different risk profile when he/she reconsulted.

A limitation of this study was the relatively low number of participating general practices in the NIVEL network for investigating a rare disease such as HIV, which has the profile of a concentrated epidemic in urban areas in our country. ${ }^{13}$ GP's testing behaviour may be different in areas of higher prevalence, although the network is designed to be nationally representative by region and population density.

STI-endemic countries were based on data from the RIVM, which also included some STI-endemic countries with a lower HIV prevalence. ${ }^{10}$ An HIV test for persons from some of these STI-endemic countries may not always be necessary, which could overestimate the people not tested for HIV according to the guideline. 
Information from the report forms and additional questionnaires may not reflect all details of GPs' clinical practice. Responder bias cannot be excluded as GPs filled in the report forms and questionnaires based on information from the medical files.

Finally, report forms were not complete for all variables as patient information from the medical record was not always available to the GP. STI care through specialised STI clinics provides free care for certain highrisk groups. Patients from high-risk groups in our study may also be tested at a STI clinic without informing the GP. This may have led to overestimating the proportion of people not tested for HIV or the importance of determinants of the acceptance or rejection of HIV testing. In addition, the number of STI-related consultations in patients from high-risk groups for whom more information was retrieved was limited because some GPs had left the NIVEL network, contact was not possible or no patient records were found.

Multiple studies have shown that HIV-positive patients frequently visit their GP prior to diagnosis, indicating that the general practice is a setting for early case finding. ${ }^{14-16}$ Our study showed that a higher proportion of HIV-positive patients from sub-Saharan African were diagnosed in general practice compared with STI clinics, which indicates that the general practice is an important setting for reaching certain high-risk groups.

A Dutch study investigating the changing patterns of undiagnosed HIV infection in the Netherlands showed that the proportions of undiagnosed HIV remained high among groups from STI-endemic countries, whereas this group is known to be late in entering care. ${ }^{2}$ We showed that in only $58 \%$ of STI-related consultations with persons from a STI-endemic country was an HIV test reported during or around the time of the consultation, which illustrates the need to explore new HIV testing strategies in this key population at risk for HIV.

A study using the national database from STI clinics in the Netherlands showed a high overall STI positivity rate among notified sexual partners of MSM, heterosexual male and female. Of the notified MSM, 21\% were newly diagnosed with HIV. ${ }^{17}$ Remarkably, in our study, $64 \%$ of the MSM notified by a partner for any STI during an STI-related consultation were not tested for HIV. An underlying reason could be that GPs may not associate certain STIs with a risk for HIV. ${ }^{16}$ However, the notification for an STI and a patient belonging to a high-risk group should be signals to suggest an HIV test. ${ }^{7} 1618$

In our study, the GP took the initiative to discuss HIV in 23\% of the HIV-related consultations. In the Netherlands, provider-initiated testing has slowly increased in the period from 1988 to 2009 (from 11\% in 1988 to $23 \%$ in 2009). ${ }^{5} \mathrm{~A}$ higher rate of testing might be achieved if provider-initiated HIV testing were to be more stimulated.

One of the reasons given for not testing a member of a high-risk group during an STI-related consultation was that the risk of HIV infection was too recent, however, data showed that an HIV test was not always reported in follow-up consultations. According to the national guidelines, GPs should have tested for HIV in the same consultation and repeated the HIV test after 3 months. The additional HIV test is the responsibility of both the patient and the GP but is not always executed in a follow-up consultation after 3 months. ${ }^{7}$ Recently, new HIV tests have been introduced to the market to detect HIV much earlier after the point of infection. ${ }^{19}$ However, the guidelines have not yet been adjusted.

A GP guideline for STIs was released in September 2013. ${ }^{7}$ This guideline addresses HIV testing in high-risk groups more clearly than before, so GPs' testing behaviour may have improved over time. The 2013 Dutch GP guideline for STI-related consultations is advising more provider-initiated HIV testing focused on HIV testing on high-risk groups. ${ }^{7}{ }^{20}$ Recording an in-depth sexual history to estimate the risk for HIV, including sexual identity, country of origin and number of partners at present and in the past 6 months, is important for adequate risk assessment. ${ }^{21}$ Patients from high-risk groups are advised to have an HIV test during an STI-related consultation and GPs are recommended to proactively discuss HIV testing, regardless of the reason for the consultation, in MSM and patients who originate from HIV-endemic regions. In our study, it was shown that the GPs do not apply the guideline literally, but take the patients' sexual behaviour and opinions into account in order to determine whether they should be tested for HIV. ${ }^{7}$ Also, GPs may find it difficult to discuss detailed questions about HIV testing. ${ }^{22}$ The choice between 'rigid' testing according to the guidelines and personal, individual patient care with more tailored implementation of guidelines rightfully remains an interaction between GP and patient.

GPs can be supported by evidence of the costeffectiveness of new additional provider-initiated HIV testing strategies to enhance early case finding. ${ }^{23}$ Details of two new, targeted HIV testing strategies have recently been published: (1) proactively offering an HIV test to individuals with HIV indicator conditions and (2) 'routine offer of an HIV test' in primary care settings where the HIV prevalence exceeds 2/1000 among those aged $15-59$ years. ${ }^{18} 2425$

This study revealed the importance of additional background information about HIV testing in high-risk groups during STI-related consultations for meaningful interpretation. As yet, however, a risk-based testing strategy has intrinsic limitations in primary care. GPs make individual decisions about testing the high-risk groups, based on a patient's risk and on opinions, indicating that the implementation of this strategy in clinical practice is complex.

GPs are important healthcare providers who diagnosed about one-third of all newly found cases of HIV. Combining new additional HIV testing strategies may help to curb the ongoing HIV epidemic. 
Author affiliations

${ }^{1}$ Department of General Practice, Division Clinical Methods and Public Health, Academic Medical Center, Amsterdam, The Netherlands

${ }^{2}$ Epidemiology \& Surveillance Unit, Centre for Infectious Disease Control, National Institute for Public Health and the Environment (RIVM), Bilthoven, The Netherlands

${ }^{3}$ Department of Sentinel Practices, NIVEL Primary Care Database, Utrecht, The Netherlands

${ }^{4}$ Stichting HIV Monitoring, Amsterdam, The Netherlands

${ }^{5}$ On behalf of the ATHENA National Observational HIV Cohort, Amsterdam, The Netherlands

${ }^{6}$ Department of Internal Medicine, Division of Infectious Diseases, Academic Medical Center, Amsterdam, The Netherlands

${ }^{7}$ University Medical Center Utrecht, Utrecht, The Netherlands

${ }^{8}$ STI AIDS Netherlands (Soa Aids Nederland), Amsterdam, The Netherlands

Acknowledgements All general practitioners who participated in the Dutch sentinel GP network from 2009 to 2013 and all participants of the ATHENA national observational HIV cohort are gratefully acknowledged. Thanks to Marianne Heshusius-van Valen for assisting in data collection.

Contributors DFMR was involved in the data collection, statistical analyses and preparation of the first draft of the manuscript. IKJ, GAD and IVvdB were involved in the data collection. IKJ and IVvdB performed further statistical analyses and wrote the final manuscript. All the authors contributed to the design and/or interpretation, provided feedback and approved the final submitted version of the manuscript.

Funding This work was supported by Aids Fonds (grant number 2012074), Amsterdam, the Netherlands.

Competing interests JEAMvB has a part-time position at STI AIDS Netherlands. The mission of this NGO is to control STI including HIV and to contribute to sexual health. A limited amount of funds is acquired via private sector cooperation, part being from pharma. An explicit code of conduct exists: http://www.soaaids.nl/sites/default/files/documenten/Corporate/ corporate_partnership_guidelines.pdf. AlvS reports grants from Dutch Ministry of Health, Welfare and Sport, during the conduct of the study; grants from Gilead Sciences, ViiV Healthcare, Bristol-Myers Squibb, European Centre for Disease Prevention and Control, outside the submitted work. The other authors declare they have no competing interests.

\section{Patient consent Obtained.}

Ethics approval According to the Medical Research (Human Subjects) Act (WMO), formal approval for this research project by a medical ethics committee was not required. The NIVEL Primary Care Database and RIVM extracts data according to strict guidelines for the privacy protection of patients and GPs. In addition, we sought and obtained permission for this work from the board of the NIVEL network.

Provenance and peer review Not commissioned; externally peer reviewed.

Data sharing statement No additional data are available.

Open Access This is an Open Access article distributed in accordance with the Creative Commons Attribution Non Commercial (CC BY-NC 4.0) license, which permits others to distribute, remix, adapt, build upon this work noncommercially, and license their derivative works on different terms, provided the original work is properly cited and the use is non-commercial. See: http:// creativecommons.org/licenses/by-nc/4.0/

\section{REFERENCES}

1. Van Sighem Al, Gras LA, Smith CJ, et al. Monitoring Report 2014: Human Immunodeficiency Virus (HIV) Infection in the Netherlands. Stichting HIV Monitoring. 2014. http://www.hiv-monitoring.nl/files/8914/ 1527/1076/SHM_Monitoring_report_2014.pdf (accessed Nov 2015).

2. Op de Coul ELM, Schreuder I, Conti S, et al. Changing patterns of undiagnosed HIV infection in the Netherlands: who benefits most from intensified HIV test and treat policies? PLOS ONE 2015;10:e0133232.

3. Cohen MS, Chen YQ, McCauley M, et al. Prevention of HIV-1 infection with early antiretroviral therapy. N Engl J Med 2011;365:493-505.

4. Van den Broek IV, Verheij RA, van Dijk CE, et al. Trends in sexually transmitted infections in the Netherlands, combining surveillance data from general practices and sexually transmitted infection centers. BMC Fam Pract 2010;11:39.
5. Donker G, Dorsman S, Spreeuwenberg P, et al. Twenty-two years of HIV-related consultations in Dutch general practice: a dynamic cohort study. BMJ Open 2013;3:e001834.

6. Cardol M, van Dijk L, de Jong JD, et al. Second National Study into disease and treatment in family practice. Family practitioner: what does the gatekeeper do? [Tweede nationale studie naar ziekten en verrichtingen in de huisartspraktijk. Huisartsenzorg: wat doet de poortwachter?]. NIVEL/RIVM, 2004. (Kernrapport 2). http://www.nivel. $\mathrm{nl} /$ sites/default/files/bestanden/ns2_rapport2.pdf (accessed Nov 2015).

7. Van Bergen J, Dekker J, Boeke A, et al. Dutch College of General Practitioners' guideline STD consultation (first revision). [NHG standaard: Het soa-consult (eerste herziening)]. Huisarts Wet 2013;56:195.

8. Trienekens SC, van den Broek IV, Donker GA, et al. Consultations for sexually transmitted infections in the general practice in the Netherlands: an opportunity to improve STI/HIV testing. BMJ Open 2013;3:e003687.

9. Donker GA. Continuous morbidity registration GP sentinel surveillance, annual report 2013. NIVEL (Netherlands Institute for Health Services Research), 2013. http://www.nivel.nl/sites/default/ files/Peilstations\%20jaarverslag\%202013\%20Engels.pdf (accessed Nov 2015).

10. National Institute for Public Health and the Environment (RIVM), Epidemiology \& Surveillance Unit, Centre for Infectious Disease Control. List of STI endemic countries, 2015. http://www.rivm.nl/ Documenten_en_publicaties/Professioneel_Praktisch/Richtlijnen/ Infectieziekten/Soa/Documenten ASG/Download/Lijst soa hiv endemische_landen (accessed Nov 2015)

11. Boesten J, Braaksma L, Klapwijk-Strumpler S, et al. Adequate record keeping in electronic patient records. [Adequate dossiervorming met het Elektronisch Patiëntendossier]. Dutch College of General Practitioners [Nederlands Huisartsgenootschap], 2013. https://www.nhg.org/sites/default/files/content/nhg_org/ uploads/richtlijn_adequate_dossiervorming_met_het_elektronisch_ patientendossier_1.pdf (accessed Nov 2015).

12. Lamberts H, Wood MR. ICPC: International Classification of Primary Care. Oxford: Oxford University Press, 1987.

13. Soetens LC, Koedijk FD, Van den Broek IVF, et al. Sexually transmitted infections, including HIV, in the Netherlands in 2012. Bilthoven, The Netherlands: National Institute for Public Health and the Environment (RIVM), 2013. http://www.rivm.nl/dsresource?objectid=rivmp:209529\& type=org\&disposition=inline\&ns_nc=1 (accessed Nov 2015).

14. Champenois K, Cousien A, Cuzin L, et al. Missed opportunities for HIV testing in newly-HIV-diagnosed patients, a cross sectional study BMC Infect Dis 2013;13:200.

15. Burns FM, Johnson AM, Nazroo J, et al. Missed opportunities for earlier HIV diagnosis within primary and secondary healthcare settings in the UK. AIDS 2008;22:115-22.

16. Joore IK, Arts DL, Kruijer MJ, et al. HIV indicator condition-guided testing to reduce the number of undiagnosed patients and prevent late presentation in a high-prevalence area: a case-control study in primary care. Sex Transm Infect 2015;91:467-72.

17. van Aar F, van Weert $Y$, Spijker R, et al. Partner notification among men who have sex with men and heterosexuals with STI/HIV: different outcomes and challenges. Int J STD AIDS 2015;26:565-73.

18. HIV in Europe. HIV indicator conditions: guidance for implementing HIV testing in adults in health care settings. 2012. http://hiveurope. eu/Portals/0/Guidance.pdf.pdf (accessed Nov 2015).

19. Cornett JK, Kirn TJ. Laboratory diagnosis of HIV in adults: a review of current methods. Clin Infect Dis 2013;57:712-18.

20. Donker G, Wolters I, van Bergen J. Care in general practices in numbers: GPs must test the high-risk groups for HIV. [Huisartsenzorg in cijfers: huisartsen moeten risicogroepen testen op HIV]. Huisarts Wet 2008;51:419.

21. Donker GA, Van den Broek IVF. Sexual anamnesis crucial in STI-consultations. [Seksuele anamnese cruciaal bij soa- consult]. Huisarts Wet 2013;56:464.

22. Deblonde J, De Koker P, Hamers FF, et al. Barriers to HIV testing in Europe: a systematic review. Eur J Public Health 2010;20:422-32.

23. Jones A, Cremin I, Abdullah F, et al. Transformation of HIV from pandemic to low-endemic levels: a public health approach to combination prevention. Lancet 2014;384:272-9.

24. National Institute for Health and Care Excellence (NICE). Increasing the uptake of HIV testing to reduce undiagnosed infection and prevent transmission among black African communities living in England. Public Health Guidance, 33, 2011. https://www.nice.org.uk/ guidance/ph33 (accessed Nov 2015).

25. National Institute for Health and Care Excellence (NICE). Increasing the uptake of HIV testing to reduce undiagnosed infection and prevent transmission among men who have sex with men. Public Health Guidance, 34, 2011. https://www.nice.org.uk/guidance/ph34 (accessed Nov 2015) 